\title{
El modelo vasco de inclusión sociolaboral de personas con discapacidad
}

\author{
Pablo Moratalla Santamaría \\ Coordinador en EHLABE \\ (Inclusión Sociolaboral-Euskal Herriko Lan Babestuaren Elkartea) (Vitoria-Gasteiz) \\ ehlabe@ehlabe.org
}

DOI: $10.1387 /$ reves. 19510

Fecha de entrada: 14/02/2017

Fecha de aceptación: 02/04/2017

\begin{abstract}
Sumario: Comparativa Euskadi-resto España empleo y discapacidad. EHLABE-modelo vasco de inclusión sociolaboral de personas con discapacidad. Características del modelo. Factores de éxito del modelo. Retos empleo y discapacidad. Bibliografía.
\end{abstract}

\section{Resumen:}

En el siguiente artículo se realiza un exhaustivo repaso del llamado Modelo Vasco de Inclusión SocioLaboral gestionado por las entidades de iniciativa social y pública de Euskadi, profundizando en sus características más significativas. Además, se definen los factores fundamentales que, 40 años después, han llevado a convertirse en un Modelo exitoso y referente tanto a nivel estatal como a nivel europeo tanto en el empleo de las personas con discapacidad en particular, como en el sector de la Economía Social en general. Finalmente, se detalla los retos más importantes a los que el sector deberá hacer frente en los próximos años con el objetivo de mejorar la empleabilidad de las personas con discapacidad en Euskadi, especialmente de los colectivos con discapacidad con mayores necesidades de apoyo.

\section{Palabras clave/descriptivas:}

Centro Especiales de Empleo/ discapacidad/ empleo/ iniciativa social/ Economía social

\section{Laburpena:}

Hurrengo artikuluan, Euskadiko ekimen sozial eta publikoko entitateek kudeatzen duten Gizarteratze eta Laneratzeko Euskal Eredua-ren ezaugarri nagusienak sakonduko dira. Gainera, Eredu hau 40 urte beranduago, bai estatu mailan bai 
Europa mailan, arrakastatsua bihurtzeko funtsezko faktoreak definituko dira, desgaitasuna duten pertsonen enpleguan bereziki, baita Ekonomi Sozialeko sektorean ere. Azkenik, Euskadin datozen urteetan desgaitasuna duten pertsonen enplegagarritasuna hobetzeko, laguntza gehien behar dutenei bereziki, sektoreak aurre egin beharko dituen erronka garrantzitsuenak zehaztuko dira.

\title{
Hitz gakoak:
}

Enplegu etxea berezia/ desgaitasuna/ enplegua / gizarte ekimena / Gizarte Ekonomia.

\begin{abstract}
:
In the following article, an exhaustive review of the so-called Basque Model of Socio-Labor Inclusion managed by the social and public initiative entities of the Basque Country is carried out, deepening its most significant characteristics. In addition, it defines the fundamental factors that, 40 years later, have led to become a successful model and refer to both state level and European level, in the employment of people with disabilities in particular, and in the Social Economics sector in general. Finally, it details the most important challenges that the sector will face in the coming years with the aim of improving the employability of people with disabilities in the Basque Country, especially those with greater support needs.
\end{abstract}

\section{Keywords:}

Special employment centre/ disability/ employment/ social initiative/ Social Economics

\section{Claves Econlit:}

J140, J210, J180.

\section{Comparativa Euskadi-resto España empleo y discapacidad}

Aunque en los siguientes apartado profundizaremos más detalladamente en los datos más significativos del empleo en Centro Especial de Empleo en Euskadi, entendemos interesante realizar una comparativa entre Euskadi y el resto del Estado de las variables más significativas relacionadas con la empleabilidad de las personas con discapacidad que nos sirva de introducción al análisis del modelo vasco de inclusión sociolaboral.

Tomando en consideración la evolución de los datos e indicadores de empleabilidad específicos del colectivo de las personas con discapacidad desde el inicio de la crisis a partir del año 2007, podemos afirmar con 
rotundidad que la situación sociolaboral del colectivo en España ha empeorado ostensiblemente los últimos ańos: se mantiene estable desde el año 2009 una baja tasa de actividad (33,9\%) muy inferior a la de la población en general $(78,1 \%)$, el acceso al empleo experimenta una progresiva reducción (tasa del $23,4 \%$ ) y la tasa de paro se ha duplicado los últimos 6 años llegando al $31 \%$.

Los últimos datos publicados de aumento del volumen de contratación (un 10,32\% en relación al 2015) de personas con discapacidad en el año 2016 parecen confirmar un cambio de tendencia en la evolución del empleo para el colectivo aunque profundizando en los datos, observamos cómo sólo el 9,6\% de los nuevos contratos formalizados fueron de carácter indefinido. Por tanto, a pesar del aumento de las contrataciones, sigue predominando una mayor temporalidad y rotación en la contratación ${ }^{1}$.

La gran mayoría del empleo para personas con discapacidad destruido en estos años de crisis en España corresponde a empleo en empresas ordinarias; por el contrario, el sector de empleo especial no sólo ha logrado mantener la mayoría del empleo sino que los Centros Especiales de Empleo que lo conforman se han convertido en el destino de muchos de las personas expulsadas del mercado de trabajo ordinario; lo que pone de manifiesto el papel fundamental que el sector, especialmente lo CEEs de iniciativa social, ha jugado en estos años de crisis como herramienta prioritaria para la inclusión social y laboral del colectivo de personas con discapacidad.

Además, el paso de esta profunda crisis económica, ha supuesto que el sector del empleo especial (ya infradesarrollado en relación a otros países del entorno) haya tenido que afrontar una difícil travesía caracterizada por factores como el retraso generalizado en el cobro de subvenciones y ayudas, retraso en el cobro de la prestación de servicios y suministro de bienes a las AAPP, pérdida de clientes y contracción del mercado, etc.

La situación del empleo para personas con discapacidad en Euskadi, no siendo ajena a la situación global en el Estado, y habiendo sufrido con dureza también las consecuencias de la crisis económica y financiera, no ha sido tan negativa en comparación al resto del país. A pesar de que también se ha producido destrucción de empleo para personas con discapacidad en empresas ordinarias el papel de lo CEEs de iniciativa social ha sido fundamental para el manteniendo del empleo ya creado y en la generación de empleo neto a través de nuevas oportunidades y como receptores de las persona expulsadas del mercado ordinario.

${ }^{1}$ Informe del Mercado de Trabajo de las personas con discapacidad Estatal 2016 INE-Instituto Nacional Estadística. 
De esta forma, Euskadi es la Comunidad Autónoma con la tasa de desempleo $(15,9 \%)$ para personas con discapacidad más baja del Estado y, a la vez, la Comunidad Autónoma con mayor tasa de actividad $(39,4 \%)$.

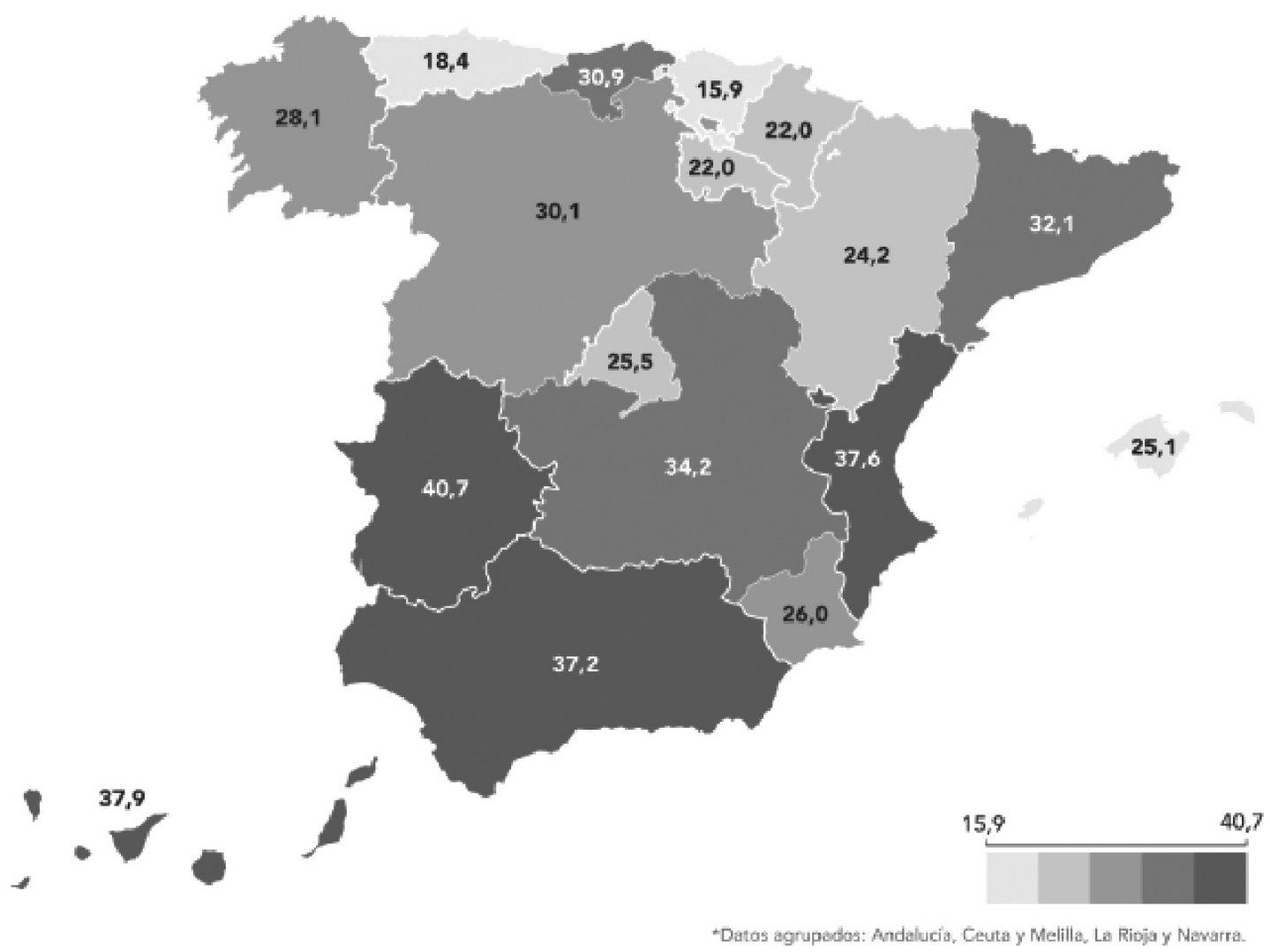

Fuente: Informe 2-Observatorio sobre discapacidad y mercado de trabajo en EspañaODISMET.

Si profundizamos en el dato de personas activas y empleadas observamos como Euskadi también se encuentra a la cabeza en el empleo del colectivo con mayores necesidades de apoyo como son las personas con discapacidad intelectual, enfermedad mental y discapacidad física y sensorial con un grado de minusvalía igual o superior al $65 \%$. 


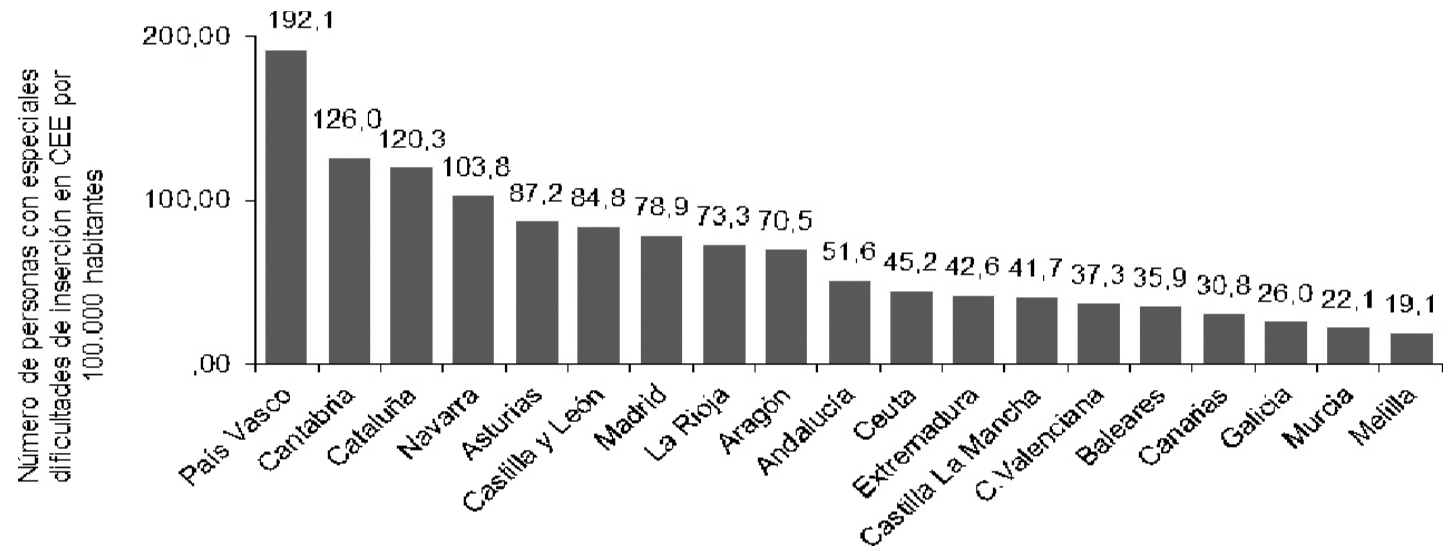

Fuente: Presente y futuro de los Centros Especiales de Empleo, KPMG 2012.

Por otro lado, y específicamente en relación al empleo especial, en Euskadi se concentra el $12 \%$ de todo el empleo en CEE a nivel estatal. Se trata por tanto, de un porcentaje muy significativo habida cuenta que Euskadi únicamente representa un 6-7\% de toda la población del país:

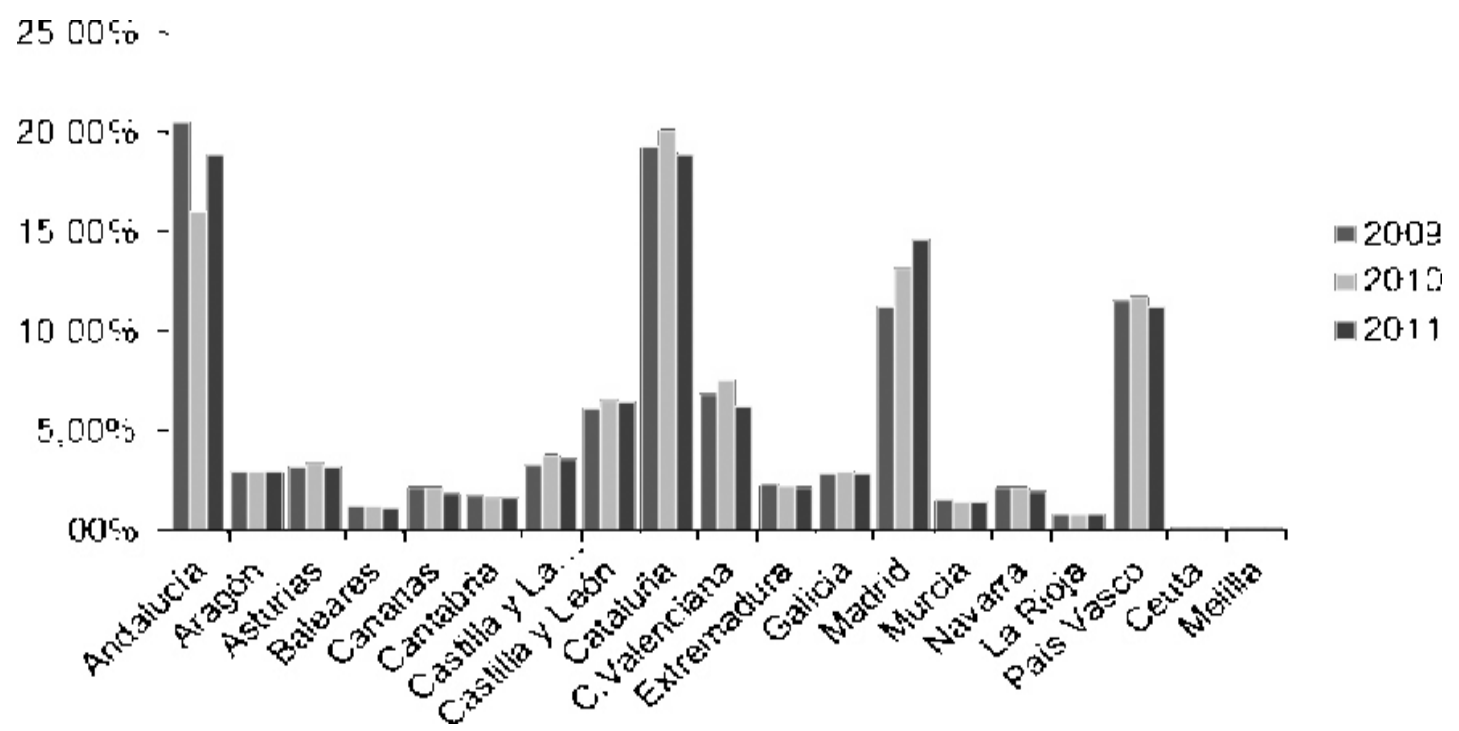

Fuente: Presente y futuro de los Centros Especiales de Empleo, KPMG 2012.

Finalmente, son las Comunidades Autónomas de Euskadi y de $\mathrm{Na}$ varra donde mayor protagonismo hay de CEEs de iniciativa social, alcanzando unos porcentajes muy significativos en relación al resto de Comunidades de España. 


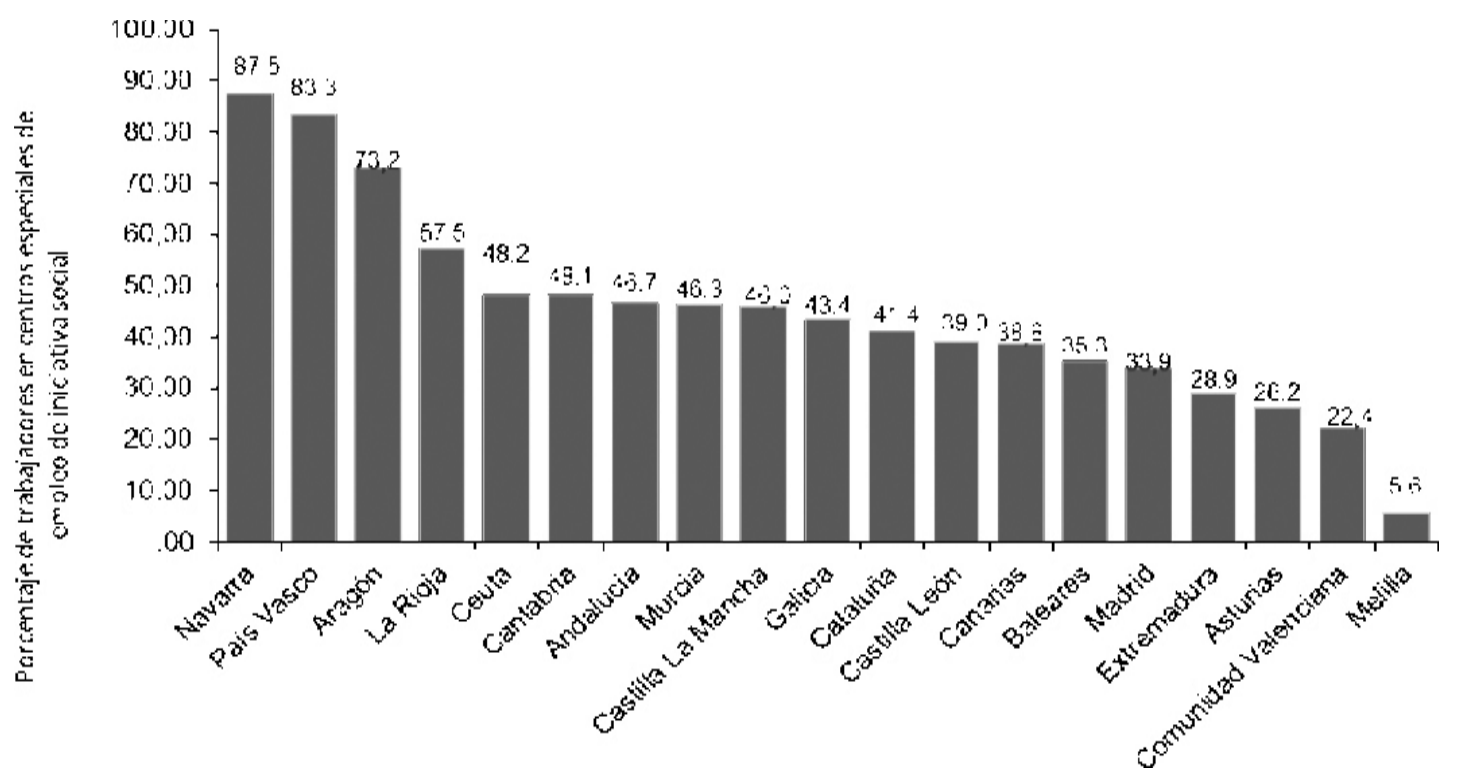

Fuente: Presente y futuro de los Centros Especiales de Empleo, KPMG 2012.

Estos porcentajes y datos de Euskadi, junto con otras características específicas que analizaremos en el siguiente apartado, resultan fundamentales para contextualizar la importancia y los resultados logrados a través del desarrollo de un modelo referente de inclusión social y laboral de personas con discapacidad.

\section{EHLABE-modelo vasco de inclusión sociolaboral de personas con discapacidad}

La inmensa mayoría de los CEEs de iniciativa social y pública de Euskadi, agrupados en la Asociación EHLABE, acumulan más de 40 años desarrollando iniciativas sostenibles, rentables y generadoras de empleo para personas con discapacidad, a pesar de que no es hasta el año 2010 cuando, a raíz de aprobación de la Ley 5/2010 de Economía Social, los CEEs se convierten de pleno derecho en una familia más de la economía social. Los CEEis de Euskadi, junto al resto de familia destacadas de la economía social (cooperativas, sociedades laborales, empresas de inserción, economía solidaria...), forman un sector que aglutina a más de 70.000 personas $(8,26 \%$ del empleo de la CAPV) que comparten sus principios fundamentales con el objetivo de lograr un economía más sostenible y una sociedad más cohesionada.

Desde su creación en el año 1987, la Asociación EHLABE ha logrado ir aglutinando bajo su paraguas a todos los CEEs de iniciativa social y pú- 
blica que operan en los tres territorios históricos. De esta forma, alrededor de EHLABE se concentra prácticamente el $95 \%$ de todas las iniciativas de empleo especial en Euskadi, que en la práctica supone 13 entidades, más de 100 centros de trabajo y más de 10.000 personas con discapacidad empleadas, ocupadas o participantes en diferentes servicios de empleabilidad (orientación laboral, formación, intermediación laboral, empleo con apoyo).

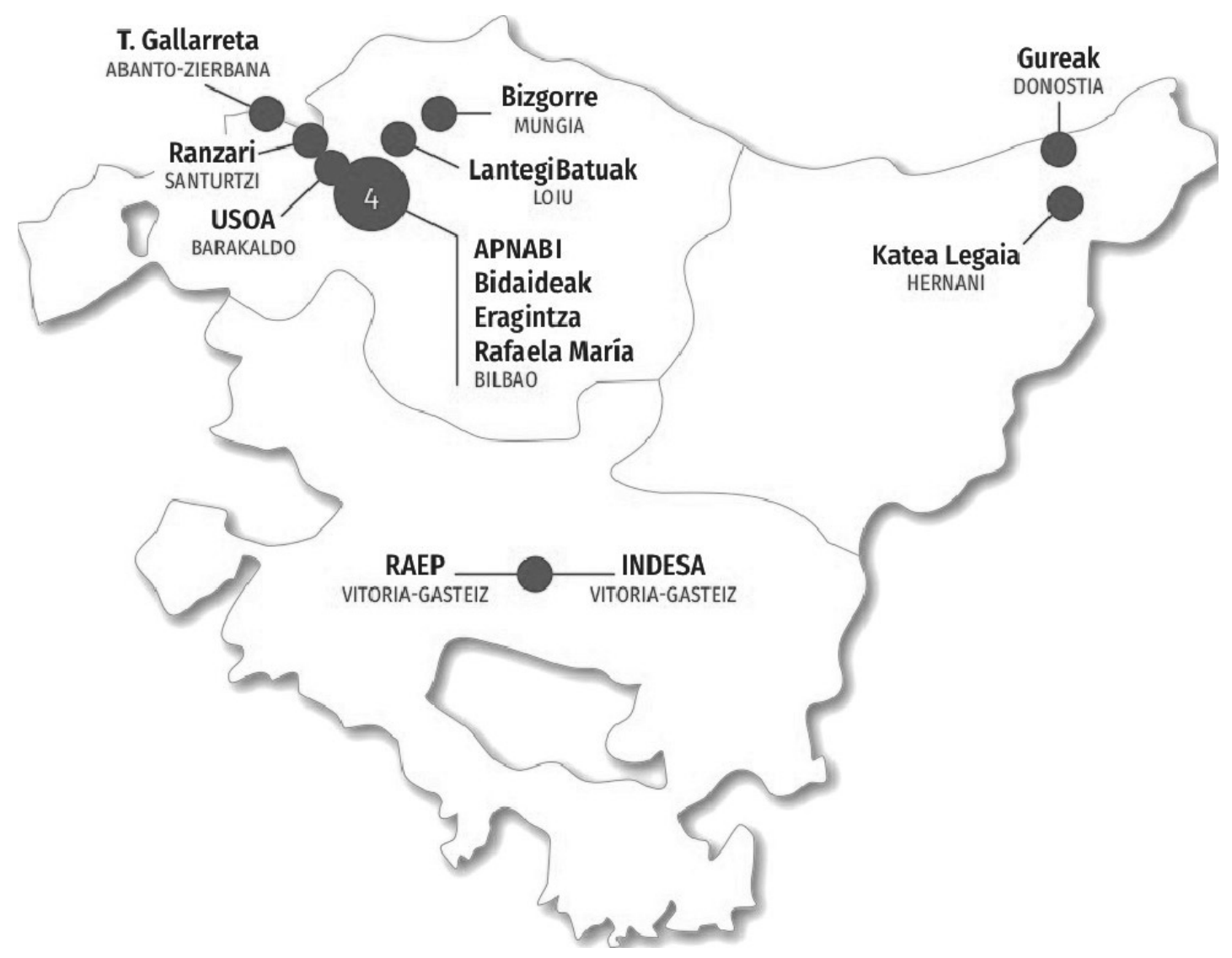

A pesar de las diferentes formas jurídicas adoptadas por las entidades asociadas a EHLABE (sociedades mercantiles, fundaciones, sociedades laborales, etc.), todas ellas son entidades surgidas de la iniciativa social o de la iniciativa pública que tienen como objetivo fundamental la generación de empleo de calidad para personas con discapacidad, especialmente las personas con discapacidad con mayores necesidades de apoyo, y que comparten todos y cada uno de los principios fundamentales de la economía social: primacía de la persona y del objeto social sobre el capital, organizaciones participativas, aplicación de resultados y beneficios al fin social, generación de empleo de calidad, etc. 


\section{Características del modelo}

A continuación analizamos las características y peculiaridades más importantes del modelo vasco que promueve la inclusión sociolaboral y que tiene como objetivo fundamental generar y gestionar oportunidades de trabajo para las personas con discapacidad:

- Gestores de itinerarios sociolaborales completos. EHLABE y sus entidades son agentes que intervienen y gestionan diversos programas de empleabilidad y, por tanto, coordinan con un enfoque inclusivo itinerarios completos de inserción laboral: desde servicios de empleabilidad fundamentales como la orientación profesional especializada, la intermediación laboral, todo tipo de formación, servicio ocupacional hasta las diferentes vías de empleo como son el empleo protegido con su objetivo final de inserción en la empresa ordinaria a través de la metodología de empleo con apoyo. Todo ello, en coordinación y colaboración con las diferentes administraciones públicas competentes, el tejido asociativo, las empresas y las propias personas.

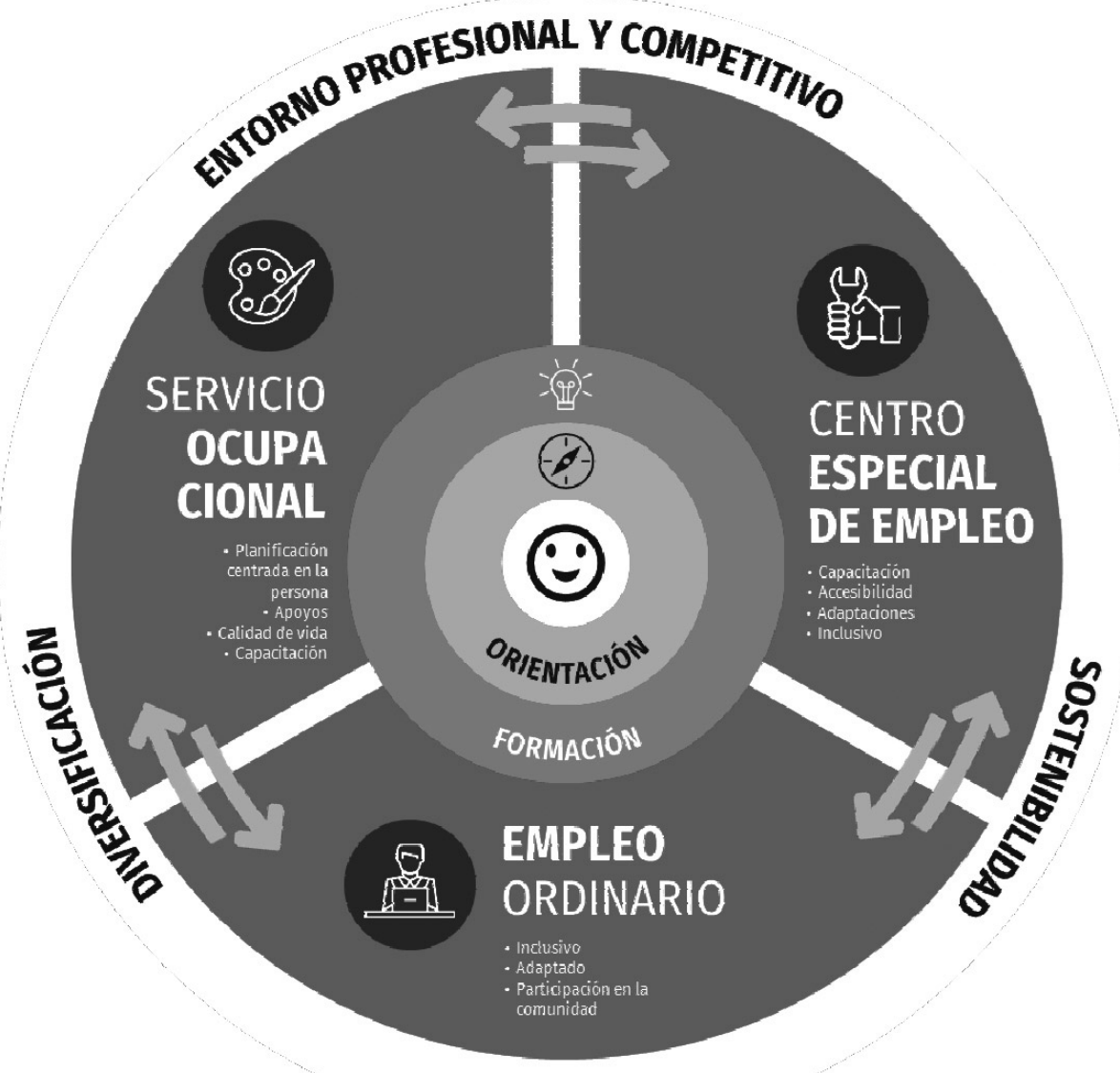


Se trata, por tanto, de un modelo flexible, innovador y que busca la potenciación de las capacidades de las personas partiendo de la premisa de que todas las personas con discapacidad cualquiera que sea su discapacidad y grado, tienen opciones a todo tipo de acciones de empleabilidad y a múltiples posibilidades de itinerarios. En este sentido, en colaboración con las propias personas se diseñan itinerarios personales en los que se pueden entremezclar diferentes servicios y apoyos en función de las necesidades y deseos de las mismas.

De esta forma, se mejora y facilita el paso y la promoción de las personas con discapacidad desde sistemas pasivos de servicios sociales a políticas activas de empleo, especialmente de los colectivos con mayores necesidades de apoyo. En el caso de Euskadi la experiencia ha demostrado, por ejemplo, las bondades de la cohabitación de modelos (servicio ocupacional y empleo protegido) y el beneficio que deriva para este colectivo para facilitar su tránsito a empleo tanto especial como ordinario.

- Tomando como base la propia definición del artículo 27 de la Convención sobre los Derechos de las personas con discapacidad, y en relación a lo comentado en el punto anterior, los CEEis de Euskadi trabajan por el derecho a un empleo en igualdad de condiciones, inclusivo, abierto y accesible ofertando, gestionando y promoviendo para las personas con discapacidad, y especialmente para las que tienen más necesidades de apoyo, una amplia gama de servicios de empleabilidad y oportunidades laborales con el fin de que las propias personas puedan decidir su itinerario y ganarse la vida mediante un trabajo libremente elegido.

Por tanto, se trata de un modelo inclusivo, centrado en la persona y en su desarrollo facilitando a las que así lo desean, no sólo en el tránsito desde el Servicio Ocupacional al empleo protegido, sino también al empleo ordinario (público o privado) a través de los ajustes, apoyos, procesos formativos y de orientación necesarios. En este sentido, cabe destacar la experiencia de más de 30 años de los CEEis de Euskadi en la gestión, en coordinación con el Servicio Público de Empleo, de los servicios de orientación profesional especializada, todo tipo de procesos formativos y del Empleo con Apoyo para la inserción laboral en entornos ordinarios de los colectivos de personas con discapacidad con mayores dificultades de empleabilidad.

- Es un modelo en el que, desde el inicio, se ha trabajado por la excelencia en la gestión de diferentes actividades empresariales en entornos altamente competitivos y profesionales y que, varias décadas después de sus inicios, ha generado miles de empleos para personas con discapacidad teniendo presencia en todas las modalidades y en casi todos los sectores; demostrando de esta manera la capacidad de las propias personas con disca- 
pacidad para desempeñar, con los apoyos oportunos multitud de trabajos diferentes en múltiples sectores. Poniendo el foco, como ya se ha comentado, en aquellas personas con mayores necesidades de apoyo.

- Finalmente, otra de las características fundamentales del modelo vasco de inclusión sociolaboral es el trabajo coordinado entre los CEEis y diferentes agentes públicos, sociales y económicos, entre los que destacan las Administraciones Públicas en sus diferentes niveles (Gobierno Vasco, Diputaciones Forales, Servicio Vasco de Empleo, INEM-SEPE). Especialmente en la coordinación de los diferentes programas y servicios de empleabilidad específicos para las personas con discapacidad.

En definitiva, basándose en modelos empresariales competitivos y profesionales, priorizando a las personas con discapacidad con mayores necesidades de apoyo y aplicando la innovación social en todos los procesos e itinerario, las entidades de la iniciativa social y pública agrupadas en torno a EHLABE han logrado convertirse en referente estatal y europeo en la generación de oportunidades de empleabilidad para el colectivo.

\section{Factores de éxito del modelo}

De las más de cuatro décadas de experiencia y trabajo de los CEEis agrupados en torno a EHLABE generando empleo para personas con discapacidad, se pueden priorizar algunos factores de éxito que han logrado posicionar al modelo vasco de inclusión sociolaboral en esa citada posición de referencia:

- En primer lugar, el valor del trabajo como medio más importante para la inclusión social de las personas con discapacidad. Desde sus inicios (hace más de cuatro décadas en muchos de los casos), todas las entidades de la órbita de EHLABE entendieron que la mejor manera para una efectiva inclusión social, especialmente de las personas con discapacidad intelectual, era la realización de una actividad laboral. Hoy en día, 40 años después, la empleabilidad de las personas con discapacidad supone la herramienta más importante en sus procesos de inclusión plena en la sociedad.

- La suma de capacidades de trabajo de personas con diversas capacidades y la implicación de las mismas en la organización y gestión de las diferentes iniciativas. Todo ello, priorizando a las personas con discapacidad con mayores necesidades de apoyo a la empleabilidad, como son las personas con discapacidad intelectual, enfermedad mental, trastorno del espectro autista, parálisis cerebral, etc. 
—Una gestión altamente profesionalizada, con una amplia diversificación de actividades y oportunidades de trabajo que ha logrado que el sector, en estos más de 40 años y a pesar de diferentes periodos de fuertes crisis y recesiones, haya logrado seguir generando empleo y ofreciendo diferentes servicios de empleabilidad a las personas con discapacidad de Euskadi.

- La influencia de un entorno, el de la sociedad vasca, con una fuerte cultura emprendedora ha tenido como consecuencia que las entidades de EHLABE en su objetivo de avanzar en el desarrollo, la empleabilidad y la inclusión sociolaboral de las personas con discapacidad, apliquen de manera constante prácticas innovadoras en la búsqueda y puesta en marcha de nuevas actividades y servicios así como en la adaptación y en los procesos de muchas de los actividades y empleos ya generados.

- El éxito del modelo vasco de inclusión sociolaboral no podría explicarse, ni hubiera llegado a las cotas de desarrollo y referencia actuales, sin la articulación de un partenariado estratégico con los diferentes agentes públicos, sociales y económicos; entre otros, las Administraciones Públicas en sus diferentes niveles (Gobierno Vasco, Diputaciones Forales, el Servicio Vasco de Empleo-Lanbide, INEM-SEPE), el Tercer Sector de Euskadi (tejido asociativo de la discapacidad, resto entidades de la economía social), agentes sociales tradicionales, Universidades, etc.

- El trabajo en red a lo largo de estos años con diversos agentes ha resultado fundamental para una gestión adecuada de los itinerarios sociolaborales y de empleabilidad de las personas con discapacidad, destacando entre ellos a las propias familias, a las propias asociaciones de la discapacidad, a los Servicio Sociales de Base, los Centros de Salud Mental, etc.

- La existencia de un marco estable de financiación pública de los diferentes programas de intervención de las personas con discapacidad que ha evitado, a pesar de las graves crisis sufridas, parones e interrupciones significativas en los diferentes programas y proyectos de empleabilidad y de inclusión sociolaboral para las personas con mayores necesidades de apoyo. Además, como ya hemos comentado anteriormente este apoyo estable público se ha producido a todos los niveles de la administración.

- Si a esa financiación estable le unimos una gestión profesional basada en la excelencia que ha llevado a un alto porcentaje de autofinanciación y de reinversión de excedentes, da como resultado que un sector de iniciativa social sólido financieramente. Esta sostenibilidad y solidez financiera no sólo ha servido de defensa en las épocas 
de crisis y de menos actividad sino que ha sido la base para la puesta en marcha de nuevas iniciativas y actividades innovadoras en nuevos nichos de mercado.

- $\mathrm{Y}$ en torno a todos estos factores, una base asociativa agrupada en EHLABE y fuertemente arraigada en el tejido social, que ha brindado de manera constante en estos más de 40 años un apoyo incondicional a las diferentes iniciativas puestas en marcha. Lo mismo cabe destacar de las iniciativas públicas, con un apoyo constante de las diferentes administraciones públicas a sus propias iniciativas.

\section{Retos empleo y discapacidad}

Como ya hemos reiterado a lo largo de todo el documento, fruto del trabajo realizado por las entidades de EHLABE, y siempre en colaboración con las diferentes Administraciones Públicas y del resto de agentes sociales y del Tercer Sector, Euskadi está a la cabeza del Estado en la generación de empleo para personas con discapacidad. Pero no debemos caer en la autocomplacencia. La situación laboral de las personas con discapacidad es, todavía hoy, peor en comparación con la población en general.

Partiendo de la base de que el empleo es un derecho universal, todos/ as estamos de acuerdo en que tener un empleo, desempeñar un trabajo nos aporta reconocimiento, autonomía, inclusión, ciudadanía... en el caso del empleo de personas con discapacidad además, ayuda a normalizar, a visibilizar las capacidades y potencialidades del colectivo evitando (o cuando menos disminuyendo) los estigmas, tabúes y prejuicios que lamentablemente hoy en día se siguen produciendo.

Cuando apenas hemos dejado atrás el periodo de crisis económica vivido la última década, en la que el deterioro del mercado laboral y de la calidad de los empleos ha golpeado con mayor virulencia a las personas más vulnerables (entre ellas las personas con discapacidad), avanzamos a pasos agigantados hacia un nuevo escenario, un nuevo paradigma para el empleo tal y como lo entendemos hoy en día. Y aunque con diversas reflexiones y opiniones acerca del escenario y desarrollo del empleo, todas comparten un futuro a medio plazo en el que miles de empleos serán destruidos debido, principalmente, a los avances de la Inteligencia Artificial (IA), la robótica, y otras tecnologías, dejando obsoletas muchas actividades que hasta ahora venían realizando las personas.

$\mathrm{Y}$ en este escenario de incertidumbre y pérdida de empleo, en el que la tecnología va a tener cada vez mayor importancia, en el que debemos trabajar diferentes retos y objetivos que ayuden a la mejora del empleo de las personas con discapacidad como eje fundamental de su inclusión social, 
adaptándonos a los nuevos cambios. En ese sentido, podemos enumerar algunos de los retos prioritarios para los próximos ańos para seguir generando más empleo, de mayor calidad que garantice las condiciones de vida y proyectos de futuro del colectivo:

\section{A nivel general}

- Seguir fomentando la generación de un empleo, si cabe, más abierto, inclusivo y accesible, en correlación con el artículo 27 de la Convención de los Derechos de las Personas con discapacidad de Naciones Unidas del año 2006 y ratificada por el estado español en 2011. Prestando especial atención a la empleabilidad de las personas con discapacidad con mayores necesidades de apoyo (discapacidad intelectual, enfermedad mental, personas con trastorno del espectro autista, etc.) y, sin perder de vista, los cambios y avances que se van a producir en los modelos de empleo en general; analizando su impacto, amenazas y oportunidades para el empleo de las personas con discapacidad en particular.

\section{En el sistema de Formación/Educación}

- En primer lugar, tenemos el reto de reducir la brecha existente entre la etapa educativa obligatoria y la formación profesional, actualizando, por ejemplo, las Aulas de Aprendizaje de tareas y desarrollando y adaptando a las necesidades de las personas con discapacidad, tanto la formación profesional básica como la Formación Profesional de Grado Medio.

En este sentido, se debe avanzar para que todo el sistema de formación normativice y desarrolle los apoyos y adaptaciones necesarios para una efectiva inclusión de las personas con discapacidad, facilitando, entre otras, itinerarios inclusivos dentro de los espacios normalizados.

- En particular, debemos seguir dando pasos y avanzando en la formación certificable con el objetivo de mejorar el acceso al empleo y de las condiciones laborales del colectivo, respondiendo a las necesidades del mercado laboral. Muy importante también, fomentar, al igual que con el resto de la población, la formación y el aprendizaje a lo largo de la vida.

- Por último, se debe seguir trabajando por facilitar y mejorar el acceso de las personas con discapacidad a la Universidad. 


\section{En el ámbito empresarial}

- Mejorar las tasas de empleo y avanzar en el tránsito de personas con discapacidad a empresas del entorno ordinario, buscando el equilibrio entre las capacidades de las personas y las necesidades de las empresas, a través de un enfoque inclusivo priorizando a aquellas personas con mayores necesidades de apoyo. Para ello, resultará imprescindible incidir en la colaboración transversal e integral entre los diferentes agentes (empresas, tercer sector de la discapacidad, agentes sociales tradicionales, administraciones públicas, etc.) que participan en los procesos de inclusión sociolaboral.

En este sentido, se hace necesario seguir visibilizando, promoviendo y potenciando una herramienta capital para mejorar estos procesos como es la Metodología del Empleo con Apoyo, que tantos años llevamos poniendo en práctica con éxito las entidades de EHLABE y del Foro de Empleo con Apoyo de Euskadi.

- Por último, y no menos importante, debemos seguir reforzando los procesos de emprendimiento entre las propias personas con discapacidad.

\section{En el ámbito de las Administraciones Públicas}

En este ámbito, tenemos 2 grandes retos en materia de empleo público para personas con discapacidad:

- En primer lugar, es necesario que desde las propias Administraciones Públicas haya mayor implicación para materializar la igualdad de oportunidades en el acceso al empleo público de las personas con discapacidad, especialmente de las personas con discapacidad intelectual y enfermedad mental, en el que hoy en día estamos en peor situación en comparativa con la mayoría de Comunidades Autónomas. En los últimos meses, se han empezado ya a dar pequeños pasos en los que la colaboración y el trabajo entre lo público (diferentes AAPP) y privado (Tercer Sector de la discapacidad) está resultando fundamental para ir avanzando.

-En segundo lugar, y aprovechando algunos más que posibles cambios normativos a materializarse en algunas Leyes (caso de la Ley Contratos Sector Público, etc.) se debe incidir con más fuerza si cabe, en la aplicación de cláusulas sociales, la reserva de mercado entre ellas, para seguir fomentando medidas de carácter positivo de inclusión laboral para personas con discapacidad. 
- Consustancial a estos 2 grandes retos, el fomento de la auto-representación del propio colectivo en las diferentes administraciones e instituciones públicas.

\section{Ámbito Envejecimiento/igualdad entre hombres y mujeres}

Y finalmente, dos áreas transversales a todas las demás: envejecimiento/ deterioro de las personas con discapacidad e igualdad entre hombres y mujeres.

- Con un colectivo de personas con discapacidad cada vez más mayor, y con la confirmación en diferentes Estudios realizados la última década que ponen de relieve procesos de envejecimiento y/o deterioro prematuro entre el colectivo de personas con discapacidad, especialmente intelectual, se hace más necesario seguir reforzando el modelo de gestión actual dirigido a favorecer el envejecimiento activo y la calidad de vida en el empleo. Este apoyo a las personas, no se puede entender sin la colaboración, tal y como se viene realizando, con diferentes agentes: desde familias, Administraciones, Tercer Sector, etc.

- En el ámbito de la igualdad entre hombres y mujeres con discapacidad, teniendo en consideración la realidad de esa «doble discriminación» de las mujeres con discapacidad, se debe seguir fomentando acciones de sensibilización, empoderamiento y visibilización de las mujeres que ayuden a la mejora de su ocupación laboral y de la calidad del empleo. En este sentido, y al margen del cumplimiento de la normativa de igualdad vigente, es necesario reforzar el proceso de empleabilidad, y todas y cada una de las partes del itinerario sociolaboral, de acciones de discriminación positiva que ayuden a paliar la actual situación de desventaja de las mujeres con discapacidad.

\section{Bibliografía}

AA.VV., Informe del Mercado de trabajo de las personas con discapacidad Estatal 2016 INE- Instituto Nacional Estadística, 2017.

AA.VV., El empleo de las personas con discapacidad Explotación de la Encuesta de Población Activa y de la Base Estatal de Personas con discapacidad. INE-Instituto Nacional Estadística 2015.

AA.VV., Informe 2-Observatorio sobre discapacidad y mercado de trabajo en España. ODISMET-Fundación ONCE, 2016. 
AA.VV., Presente y futuro de los Centros Especiales de Empleo. KPMG, 2012.

BAREA TEJEIRO, J. (dir.), MONZÓN CAMPOS, J.L., AA.VV. (2008): Economía social e inserción laboral de las personas con discapacidad en el País Vasco, Fundación BBVA.

BENGOETXEA ALKORTA, A. (2014): «Economía social e inserción laboral de las personas con discapacidad", Revista Vasca de Administración Pública, 99100.

CARDENAL CARRO, M./HIERRO HIERRO, J. (2008), Nuevos caminos hacia la integración sociolaboral y la igualdad y no discriminación en el empleo de las personas con discapacidad: estrategia global de acción para el empleo de personas con discapacidad 2008-2012, Aranzadi Social, 17.

IRIONDO MÚGICA, I./VELÁZQUEZ ANGONA, F.J. (2016), «Integración laboral de las personas con discapacidad en los principales países de la UE», Revista del Ministerio de Empleo y Seguridad Social, 121.

MARTÍNEZ-SAGARRA GONZÁLEZ, J., (2010): «Economía social e integración laboral de personas con discapacidad», en Fernández Arufe, J.E. (coord.), Estudios de economía social, Universidad de Valladolid, 2010. 